\title{
Sex chromosome complement contributes to sex differences in coxsackievirus B3 but not influenza A virus pathogenesis
}

\author{
Dionne P Robinson ${ }^{1 *}$, Sally A Huber ${ }^{2}$, Mohamad Moussawi ${ }^{2}$, Brian Roberts ${ }^{2}$, Cory Teuscher $^{3}$, Rebecca Watkins ${ }^{4}$,
} Arthur P Arnold ${ }^{4}$ and Sabra L Klein ${ }^{1}$

\begin{abstract}
Background: Both coxsackievirus B3 (CVB3) and influenza A virus (IAV; H1N1) produce sexually dimorphic infections in C57BL/6 mice. Gonadal steroids can modulate sex differences in response to both viruses. Here, the effect of sex chromosomal complement in response to viral infection was evaluated using four core genotypes (FCG) mice, where the Sry gene is deleted from the $Y$ chromosome, and in some mice is inserted into an autosomal chromosome. This results in four genotypes: XX or XY gonadal females (XXF and XYF), and XX or XY gonadal males (XXM and XYM). The FCG model permits evaluation of the impact of the sex chromosome complement independent of the gonadal phenotype.
\end{abstract}

Methods: Wild-type (WT) male and female C57BL/6 mice were assigned to remain intact or be gonadectomized (Gdx) and all FCG mice on a C57BL/6 background were Gdx. Mice were infected with either CVB3 or mouseadapted IAV, A/Puerto Rico/8/1934 (PR8), and monitored for changes in immunity, virus titers, morbidity, or mortality.

Results: In CVB3 infection, mortality was increased in WT males compared to females and males developed more severe cardiac inflammation. Gonadectomy suppressed male, but increased female, susceptibility to CVB3. Infection with IAV resulted in greater morbidity and mortality in WT females compared with males and this sex difference was significantly reduced by gonadectomy of male and female mice. In Gdx FCG mice infected with CVB3, XY mice were less susceptible than XX mice. Protection correlated with increased CD4+ forkhead box P3 (FoxP3)+ T regulatory (Treg) cell activation in these animals. Neither CD4+ interferon (IFN) $\gamma(T$ helper 1 (Th1)) nor CD4+ interleukin (IL)-4+ (Th2) responses differed among the FCG mice during CVB3 infection. Infection of Gdx FCG mice revealed no effect of sex chromosome complement on morbidity or mortality following IAV infection.

Conclusions: These studies indicate that sex chromosome complement can influence pathogenicity of some, but not all, viruses.

\section{Background}

Males and females differ in their susceptibility to a variety of viral pathogens [1]. The mechanisms for this sexual dimorphism are complex and can involve hormonal, behavioral and genetic factors. Females typically generate enhanced immune responses compared to males [2-4], which can accelerate virus clearance and reduce

\footnotetext{
* Correspondence: dirobinso@jhsph.edu

'The W Harry Feinstone Department of Molecular Microbiology and Immunology, The Johns Hopkins Bloomberg School of Public Health, Baltimore, MD 21205, USA

Full list of author information is available at the end of the article
}

virus load, but can be detrimental by causing immunopathology or the development of autoimmune disease. Immunity to viruses varies with changes in hormone concentrations caused by natural fluctuations over the menstrual or estrous cycle, contraception use, and pregnancy [5]. Estradiol influences multiple aspects of both innate and adaptive immunity including: enhancing dendritic cell differentiation and antigen presentation [6], suppressing lymphoid cell expression of tumor necrosis factor (TNF) $\alpha$ and interleukin (IL)-6 [7,8], increasing lymphoid cell production of IL-4 and interferon (IFN) $\gamma$ 
[9-11], increasing immunoglobulin synthesis [12], inhibiting B cell apoptosis [13], suppressing $T$ and B cell lymphopoiesis [14], and promoting forkhead box P3 (FoxP3)+ T regulatory cell development [15-17]. In contrast, androgens are usually immunosuppressive and inhibit both humoral and cellular immunity, including natural killer cell activity $[18,19]$.

Although direct effects of gonadal steroids cause many sex differences in physiology, some sex differences are also caused by the inherent imbalance in the expression of genes encoded on the X and Y chromosomes [20-22]. Many genes on the $\mathrm{X}$ chromosome regulate immune function and play an important role in modulating sex differences in the development of immune-related diseases [23]. These immune-related genes code for proteins ranging from pattern recognition receptors (for example, $T \operatorname{lr} 7$ and $T \operatorname{lr} 8$ ) to cytokine receptors (for example, $I l 2 r g$ and Il13ra2) and transcriptional factors (for example, Foxp3) [24]. As a result, X-linked immunodeficiencies are more prevalent in males. However, autoimmune diseases occur more frequently in females, probably as a result of differences in effects of gonadal hormones and sex chromosome genes [23,25].

The Sry gene on the Y chromosome causes testes formation and testosterone synthesis leading to maletypical development of many phenotypes, whereas the absence of Sry results in ovaries and female-typical development [26]. The 'four core genotypes' (FCG) mouse model has been developed to investigate the impact of sex chromosomes (XX vs XY) and gonadal type (testes vs ovaries) on phenotypes. In FCG mice, Sry is deleted from the Y chromosome and an Sry transgene is inserted onto an autosome. Deletion of the Sry gene results in XYminus (XY-) mice that are gonadal females (that is, with ovaries) whereas insertion of the Sry transgene onto an autosome in XX or $\mathrm{XY}$ - mice (XXSry and XY-Sry) results in gonadal males (that is, with testes). The FCG are: XX gonadal females (XXF), XY - gonadal females (XYF), XXSry gonadal males (XXM) and XY-Sry gonadal males (XYM). Depletion of gonadal steroids by gonadectomy of FCG mice unmasks profound effects of sex chromosome complement on behavior, brain function, renal function, and susceptibility to autoimmune disease [22,27]. In experimental autoimmune encephalitis (EAE) and lupus, for example, the presence of the XX sex chromosome complement worsens disease progression, relative to that in $\mathrm{XY}$ mice, and results in decreased production of IL-4, IL-5, and IL-13, but increased IL$13 R \alpha 2$ expression on dendritic cells [27].

Whether sex chromosome complement modulates sex differences in response to viruses has not been examined. Sexual dimorphism in picornavirus infections, including coxsackievirus B3 (CVB3), in mice is well documented with males showing more severe disease than females [28-30]. In contrast, influenza A virus (IAV) infection is more severe in females than males $[31,32]$. Much of the sexual dimorphism in the outcome of infection with either CVB3 or IAV depends upon the effects of gonadal hormones on immune responses to viral infection [1]. Whether sex chromosome complement also contributes to sex differences in response to viruses was explored in this study. These studies demonstrate that sex chromosome complement contributes to the severity of disease caused by CVB3 but not IAV suggesting that sex chromosomes can impact susceptibility to some but not all viral infections.

\section{Methods}

\section{Animals}

Adult wild-type (WT) male and female C57BL/6 mice were purchased either from NCI (Frederick, MD, USA) or Jackson Laboratories (Bar Harbor, ME, USA). Mice were age matched to the FCG mice in our facilities. FCG mice backcrossed to a Jackson Labs C57BL/6 background for more than 15 generations were used to obtain litters consisting of XXF, XYF, XXM, and XYM. All experimental FCG mice were bred at UCLA and then sent to the University of Vermont or Johns Hopkins University for viral infection. Mice were maintained at five per microisolator cage under standard housing conditions with a 14:10 light/dark cycle and ad libitum access to food and water. All experiments were approved by either the Johns Hopkins University or University of Vermont Animal Care and Use Committee and conducted using approved biosafety level 2 practices and procedures.

\section{Gonadectomy}

All FCG ( $n=6-9$ per group) and half of the WT animals ( $n=7-10$ per group) were gonadectomized (Gdx) to remove concurrent effects of sex steroids, which can mask effects of sex chromosomes [33]. For bilateral gonadectomy, females and males were anesthetized with an intramuscular injection of a ketamine $(80 \mathrm{mg} / \mathrm{kg}) /$ xylazine $(6 \mathrm{mg} / \mathrm{kg}$ ) cocktail (Phoenix Pharmaceutical, St Joseph, MO, USA) and the testes were removed from males and the ovaries from females using aseptic technique as described previously [34-36]. Animals were sutured and given several weeks to recover from surgery. All mice were gonadectomized at 8-10 weeks of age. Surgery was performed at UCLA for CVB3 studies and at Johns Hopkins for IAV studies.

\section{CVB3 infection}

The H3 variant of CVB3 was made from an infectious cDNA clone as described previously [37]. Mice were infected at 15-25 weeks of age with 100 plaque-forming 
units (PFU) of virus intraperitoneally in $0.5 \mathrm{ml}$ phosphate-buffered saline (PBS) and killed 7 days later.

\section{IAV infection}

The mouse-adapted IAV, A/Puerto Rico/8/1934 (PR8; H1N1; courtesy of Maryna C Eichelberger at the Food and Drug Administration), was used for inoculation. Male and female mice $(n=6-10$ per experimental group) were infected at 18-22 weeks of age. Mice were anesthetized with ketamine-xylazine and inoculated intranasally with $10^{2} 50 \%$ tissue culture infective dose $\left(\mathrm{TCID}_{50}\right)$ of PR8 in Dulbecco's modified Eagle medium. Body mass, rectal temperature, and mortality were monitored daily for 21 days.

\section{Organ CVB3 titers}

Hearts were aseptically removed from the animals, weighed, homogenized in RPMI 1640 medium containing $5 \%$ fetal bovine serum (FBS), L-glutamine, streptomycin and penicillin. Cellular debris was removed by centrifugation at $300 \mathrm{~g}$ for $10 \mathrm{~min}$. Supernatants were diluted serially using tenfold dilutions and tittered on Hela cell monolayers by the plaque-forming assay [38].

\section{Histology}

Tissue was fixed in $10 \%$ buffered formalin for $48 \mathrm{~h}$, paraffin embedded, sectioned, and stained by hematoxylin and eosin. Slides were coded and read blindly using a 0 to 4 scale as published previously [39].

\section{Antibody depletion of $\mathrm{T}$ cells in vivo}

Mice were injected intraperitoneally with $100 \mu \mathrm{g}$ monoclonal anti-CD3 antibody (clone 17-A2) or rat IgG2b (clone A95-1) in $0.5 \mathrm{ml}$ PBS on day -3 and +1 relative to injection of virus. $\mathrm{T}$ cell depletion was determined by flow cytometry of spleen cells as described below.

\section{Flow cytometry}

$\mathrm{CD} 4+\mathrm{IFN} \gamma+$ cells were determined by intracellular cytokine staining [39]. $10^{5}$ spleen cells were cultured for $4 \mathrm{~h}$ in medium containing $10 \mu \mathrm{g}$ of Brefeldin A (BFA; Sigma, St. Louis, MO), $50 \mathrm{ng} / \mathrm{ml}$ phorbol myristate acetate (PMA; Sigma), and $500 \mathrm{ng} / \mathrm{ml}$ ionomycin (Sigma); washed; labeled with a 1:100 dilution of Alexa 647 antiCD4 (clone GK1.5) or Alexa 647 rat IgG2b (clone A951 ); fixed in $2 \%$ paraformaldehyde; permeabilized with $0.5 \%$ saponin; and labeled with 1:100 dilutions of PE anti-IFN $\gamma$ (clone XMG1.2) and Alexa647 anti-IL4 (clone 11B11) or PE and Alexa647 rat IgG1 (clone R3-34). All antibodies were from BD Biosciences/Pharmingen (Franklin Lakes, NJ, USA). T regulatory cells were identified using the Mouse T Regulatory Cell Staining Kit (eBioscience, San Diego, CA, USA) according to manufacturer's directions. Cells were analyzed using a BD
LSR II flow cytometer with a single excitation wavelength $(488 \mathrm{~nm})$ and a band filter for PE $(575 \mathrm{~nm})$. The excitation wavelength for Alexa 647 is $643 \mathrm{~nm}$ and a band filter of $660 / 20 \mathrm{~nm}$. The cell population was classified for cell size (forward scatter) and complexity (side scatter). At least 10,000 cells were evaluated. Positive staining was determined relative to isotype controls.

\section{Statistical analyses}

Survival following infection was compared among experimental groups using log rank sum and $\chi^{2}$ analyses. Other dependent measures were analyzed using two-way analysis of variance (ANOVA) or multivariate ANOVA (MANOVA) with sex/hormone status/sex chromosome complement and days post inoculation as the independent variables. Significant interactions were further analyzed using planned comparisons or the Tukey method for pairwise multiple comparisons. Mean differences were considered statistically significant if $P<$ 0.05 .

\section{Results}

Sex chromosome complement impacts susceptibility to CVB3 infection

Gonadally intact, WT male and female C57BL/6 mice were infected with CVB3 and by 7 days post infection, 5/10 WT male and 0/10 WT female mice died or were moribund and required killing $\left(\chi^{2}, P<0.01\right)$. WT male C57BL/6 mice develop significantly greater myocarditis than WT female mice (two-way ANOVA sex effect $P<$ 0.005), but had similar cardiac virus titers (Figure 1). Gonadectomy of WT male mice reduced CVB3 pathogenicity, whereas gonadectomy of WT female mice increased CVB3 pathogenicity and in the absence of sex hormones, Gdx males became less susceptible to myocarditis than Gdx females (Figure 1a; two-way ANOVA sex $\times$ gonadal status effect $P<0.00005$ ). This study demonstrates that sex hormones are primarily involved in myocarditis susceptibility in males, whereas sex hormones in females suppress myocarditis susceptibility. In contrast, no significant differences were observed in cardiac virus titers between intact and Gdx animals or between WT male and WT female mice, indicating that pathology is not directly related to CVB3 infection of the myocardium (Figure 1b).

$\mathrm{T}$ cells are crucial to CVB3 pathogenesis since mice made deficient of these effectors by thymectomy, irradiation and bone marrow reconstitution fail to develop myocarditis despite high virus titers in the heart [37]. To demonstrate a role for $\mathrm{T}$ cells in mediating sex differences in CVB3 pathogenesis, WT male mice were injected on days -3 and +1 relative to infection with 100 $\mu \mathrm{g}$ of monoclonal IgG isotype immunoglobulin or antiCD3, which depleted $>93 \%$ of CD3+ T cells in the 


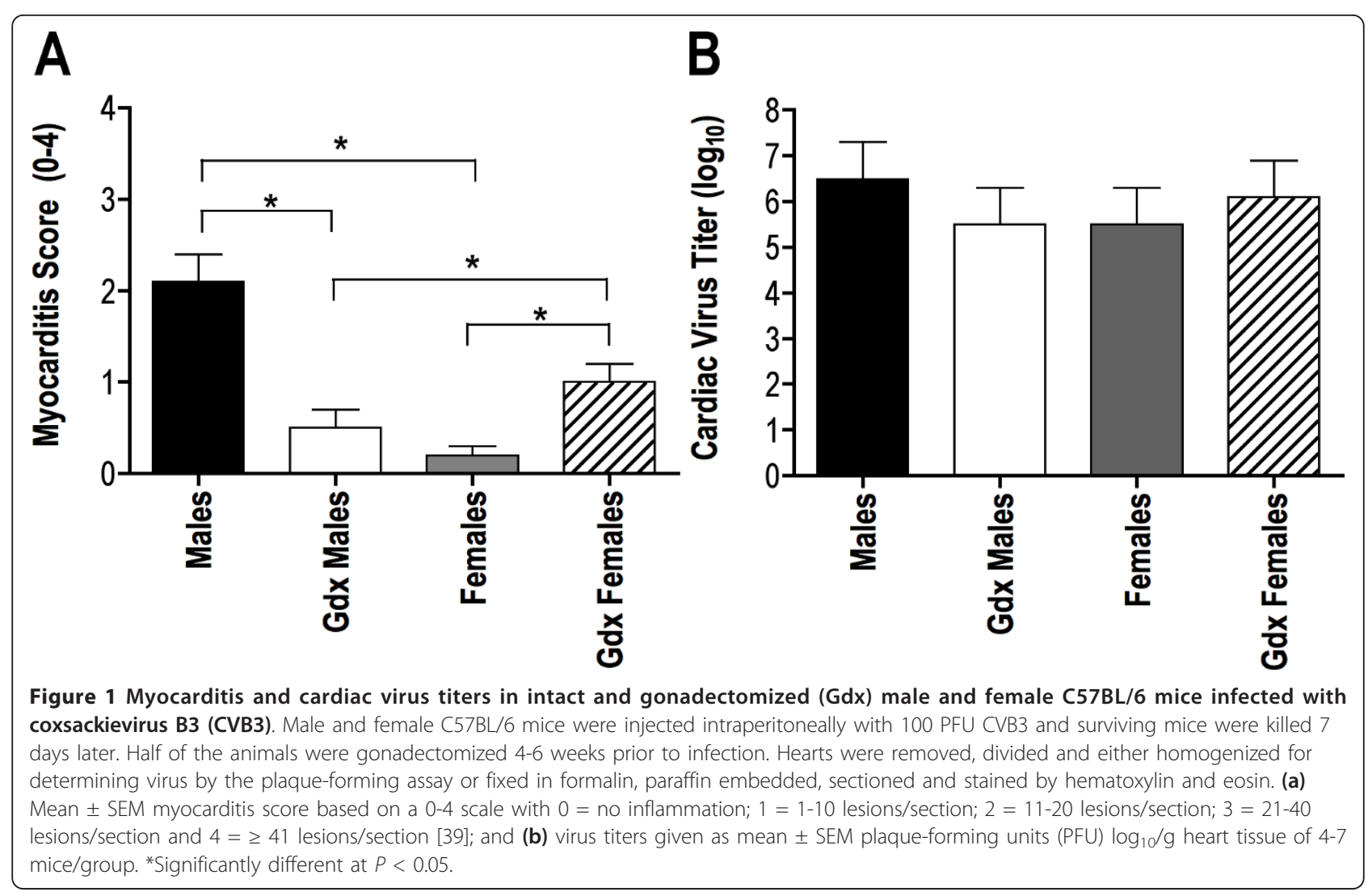

animals. T cell deficient male mice developed less myocarditis compared to immunoglobulin treated males (Figure 2; t test $P<0.05$ ). T cell depletion had no significant effect on cardiac virus titers confirming earlier studies that CVB3 clearance during primary infection is not dependent on $\mathrm{T}$ cell responses [40].
The possibility that sex chromosome complement influences CVB3-induced myocarditis was investigated by infecting Gdx FCG mice and evaluating myocarditis and virus titers 7 days post infection (Figure 3). Myocarditis scores showed a significant effect of sex chromosome complement, in which XX mice developed

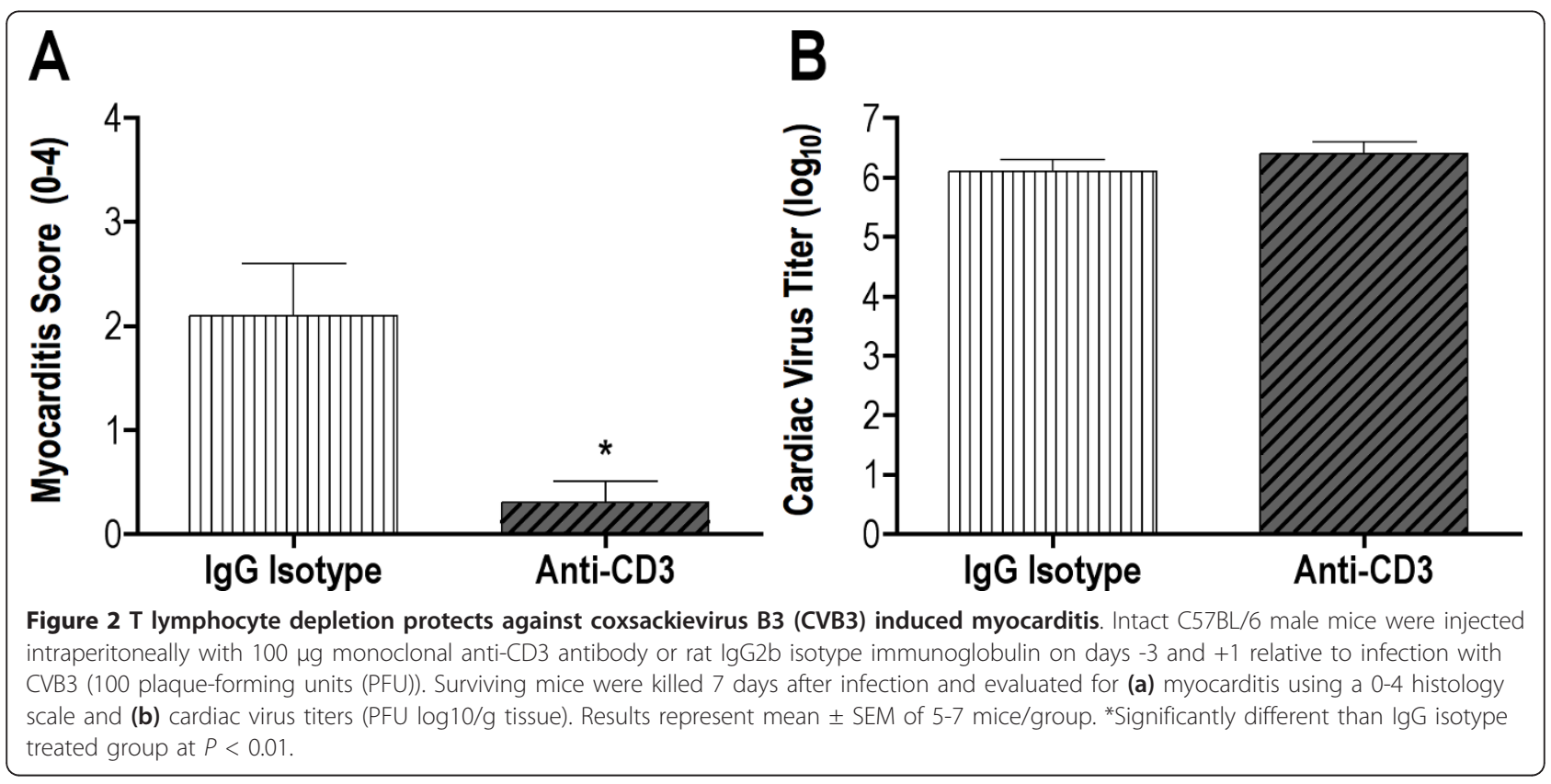




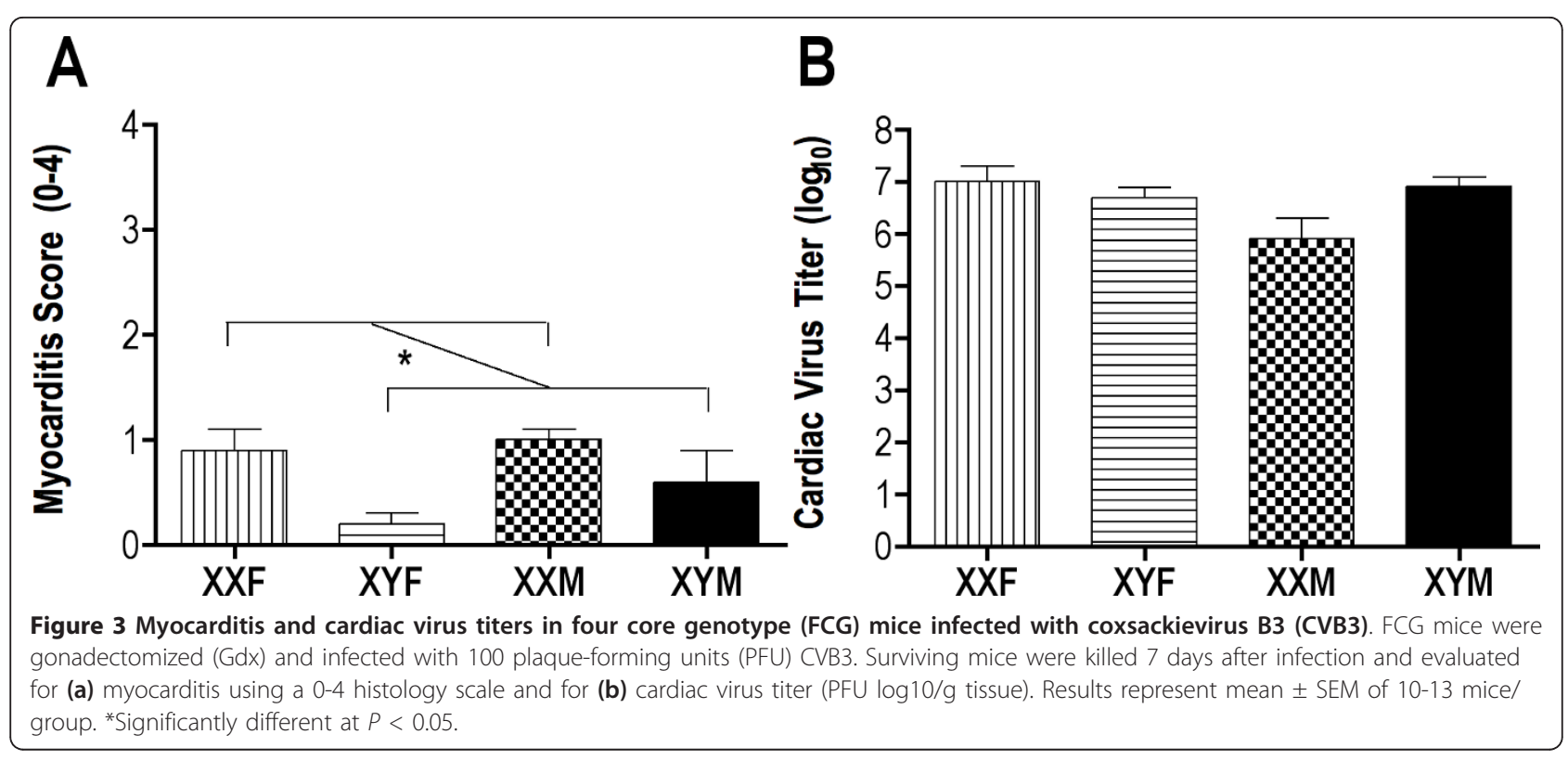

significantly more myocarditis than XY mice, irrespective of their gonadal sex (two-way ANOVA sex chromosome complement effect $P<0.009$ ). There were no differences in cardiac virus among the FCG mice. To evaluate the mechanism by which sex chromosome complement impacts CVB3 myocarditis, spleen cells from FCG mice were isolated and evaluated by flow cytometry for CD4+IFN $\gamma+$ (T helper 1 (Th1)), CD4 + FoxP3+ (T regulatory) or CD4+IL-4+ (Th2) cell responses. No significant difference in Th2 cell responses was observed among the FCG mice (data not shown). Gonadal females had significantly greater Th1 cell responses than gonadal male mice, regardless of their sex chromosome complement (Figure 4a; twoway ANOVA gonadal sex effect $P<0.0006)$. In contrast, higher $\mathrm{T}$ regulatory cell numbers were observed at day 7 post infection in $\mathrm{XY}$ than $\mathrm{XX}$ mice, irrespective of gonadal sex (Figure 4b; two-way ANOVA sex chromosome complement effect $P<0.006$ ). Taken together, these data illustrate that both gonadal hormones and sex chromosomes contribute to CVB3 pathogenicity.

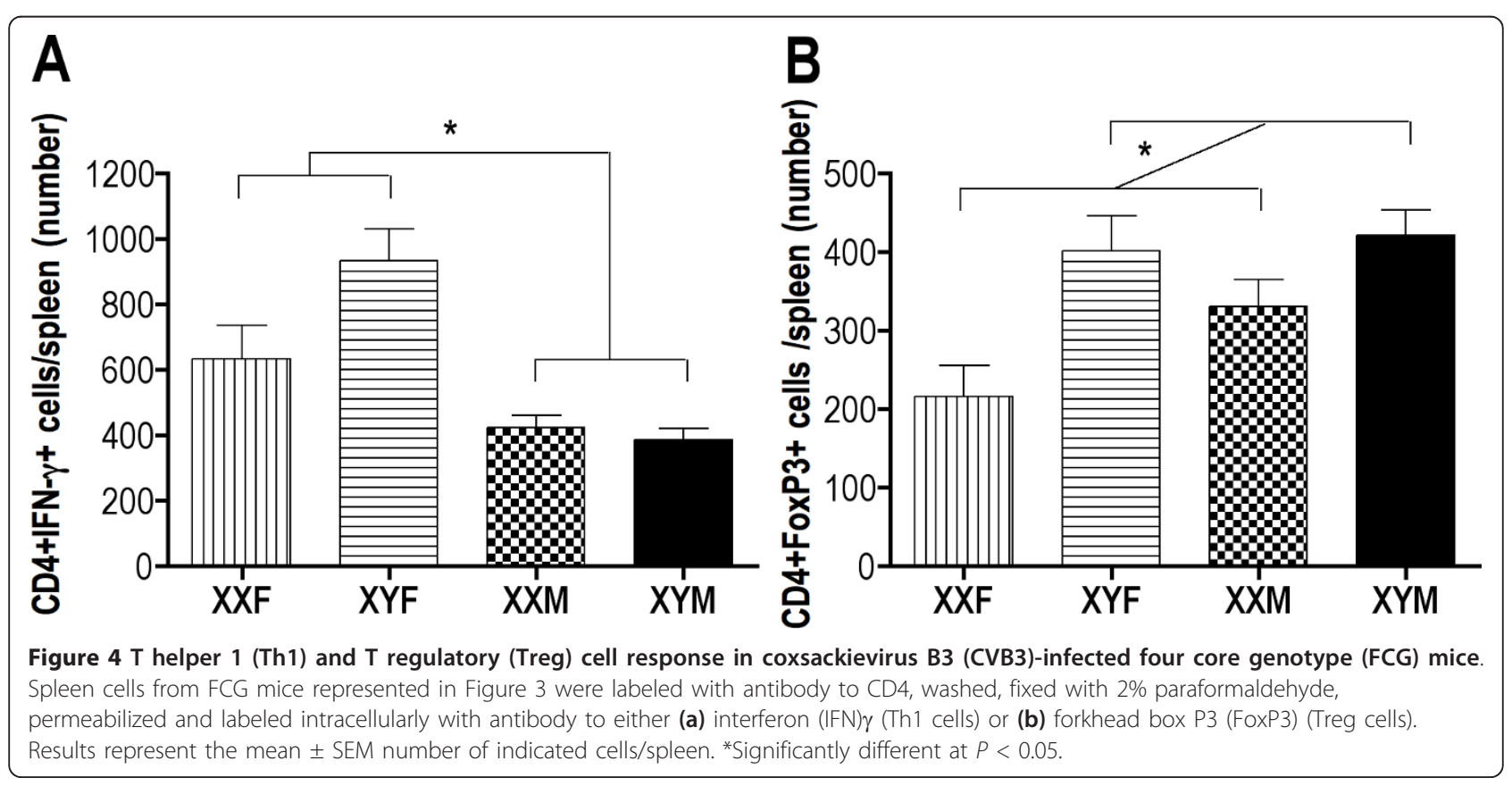


Sex chromosome complement does not impact susceptibility to IAV infection

Sex biases also exist in response to IAV infection $[31,32,41]$. To begin our analyses, we inoculated male and female C57BL/6 mice with IAV and morbidity and mortality were evaluated over a 21-day period in gonadally intact WT mice that were older than in previous studies [32] (that is, animals were 18-22 weeks of age to be age matched to FCG mice). Although males and females lost a similar percentage of body mass, females experienced a greater reduction in rectal temperature than males during infection (Figure 5a, b; MANOVA sex $\times$ day interaction $P<0.0001)$. Survival was also significantly reduced among females, in which fewer females survived infection and females died sooner than their male counterparts (Figure $5 \mathrm{c}$; $\log$ rank $P<0.05$ ). These data illustrate that sex differences in response to IAV infection are observed among older adult mice, corresponding to the sex differences previously shown in younger animals (that is, animals that were 9-11 weeks of age) [32].

To determine if deprivation of sex steroid hormones could abolish sex differences in morbidity and mortality from IAV infection, WT adult male and female C57BL/ 6 mice were gonadectomized and infected with IAV. Gdx females lost more weight than Gdx males (Figure 6a; MANOVA treatment $\times$ day interaction $P<0.01$ ), but showed a similar reduction in rectal temperature as Gdx males (Figure 6b). The proportion of Gdx females and males that died as well as the rate of death were similar following infection (Figure 6c). These data illustrate that sex steroid deprivation reduces, and in some cases eliminates, the sex difference in IAV pathogenesis.

To examine whether sex chromosome complement affects susceptibility to IAV infection, responses to infection were examined in Gdx FCG mice [33]. All FCG mice lost a similar percentage of body mass and experienced a similar reduction and recovery in rectal temperature during the course of infection (Figure 7a, b). The proportion of mice surviving infection was similar among XXF, XYF, XXM, and XYM mice (Figure 7c). Although not statistically significant, among those animals that died, the average day of death was slightly later for gonadal male (XXM and XYM) than gonadal female (XYF and XXF) mice (Figure 7d; two-way ANOVA gonadal sex effect $p=0.056$ ). Taken together, these data suggest that sex chromosome complement does not affect susceptibility to IAV in C57BL/6J mice.

\section{Discussion}

Sex differences in response to viral infections are well documented [1]. In many cases, these differences are

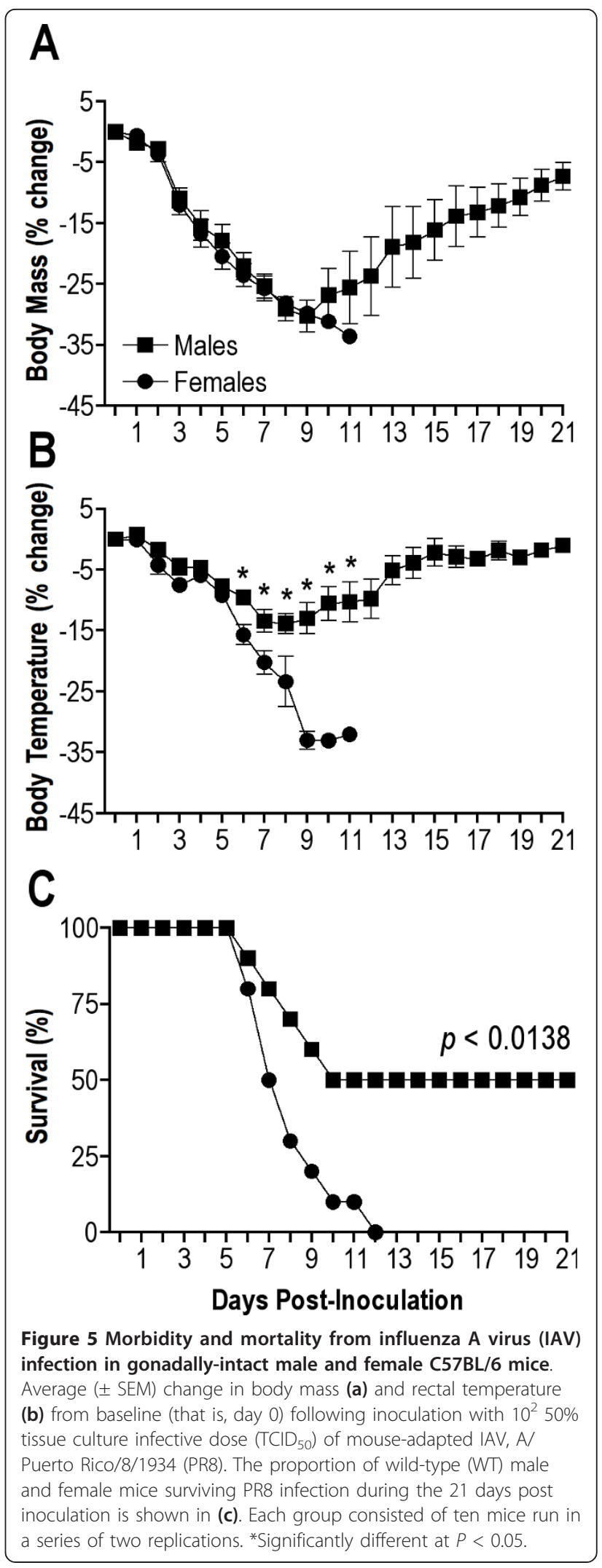


A
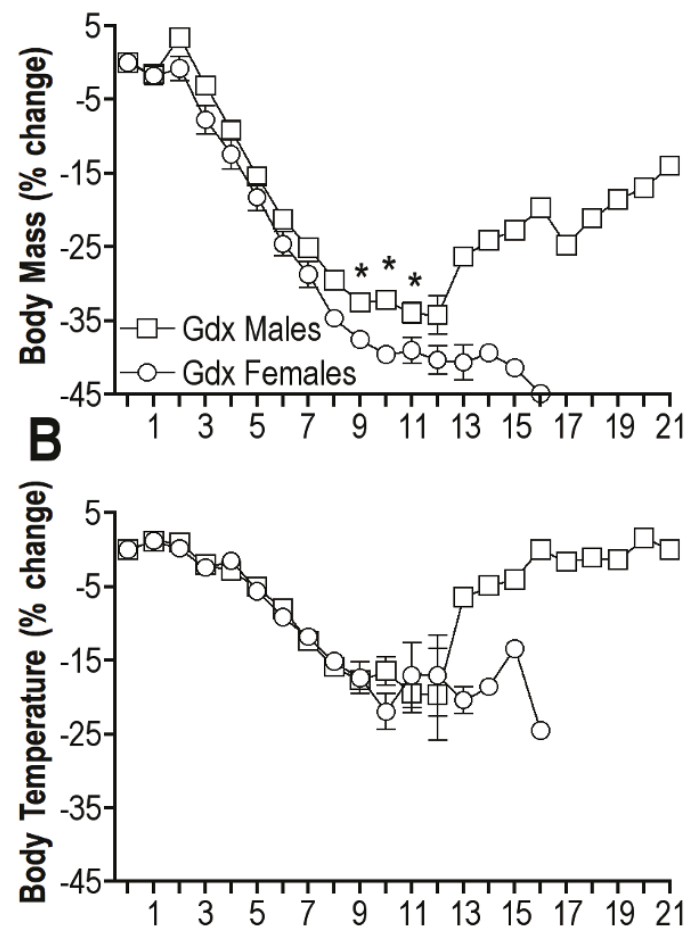

C

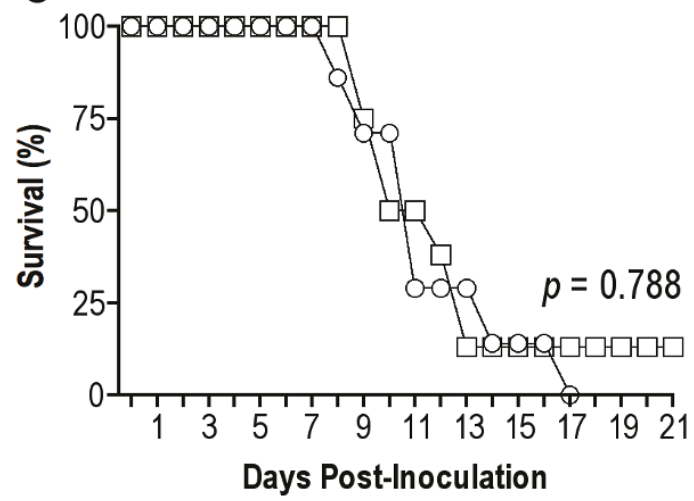

Figure 6 Morbidity and mortality from influenza A virus (IAV) infection in gonadectomized (Gdx) male and female C57BL/6 mice. Average $( \pm$ SEM) change in body mass (a) and rectal temperature (b) from baseline (that is, day 0) following inoculation with $10^{2} 50 \%$ tissue culture infective dose $\left(T_{C I D_{50}}\right)$ of mouse-adapted IAV, A/Puerto Rico/8/1934 (PR8). The proportion of Gdx male and female mice surviving PR8 infection during the 21 days post inoculation is shown in (c). Each group consisted of 7-8 mice run in a series of 2 replications. *Significantly different at $P<$ 0.05 .

modulated by the effects of gonadal hormones, including testosterone and estradiol, on immune responses to infection [1]. This communication confirms an important role for testicular and ovarian secretions in the response to viral infection, and also shows that sex chromosome complement impacts the pathogenicity of CVB3 but not IAV infections in mice.

Host immunity can play a significant role in either recovery or pathogenesis from both picornavirus and influenza virus infections. For picornaviruses, host $\mathrm{T}$ cell immunity is particularly detrimental and in CVB3 myocarditis [42], Theiler's virus encephamyelitis [43], and encephalomyocarditis virus-induced diabetes [44], virus infection induces autoimmunity to tissue antigens by antigenic mimicry or epitope spreading. Autoimmune effectors rather than direct virus cytopathic effects are the dominant mechanism of morbidity and mortality in response to these viruses. $\mathrm{T}$ regulatory cell activity abrogates autoimmune $\mathrm{T}$ cell responses, morbidity and mortality following picornavirus infection [45]. In the present study, activation of $\mathrm{T}$ regulatory cells was increased in Gdx XYF and XYM mice compared to Gdx $\mathrm{XXM}$ and XXF mice, resulting in preferential protection of these mice from CVB3. Previous studies have linked activation of FoxP3 $+\mathrm{T}$ regulatory cells with resistance to CVB3 induced myocarditis, which is consistent with the current finding $[39,45]$. Foxp 3 , the T regulatory cell transcriptional factor, is encoded on the $\mathrm{X}$ chromosome. It is therefore highly probable that the increased $\mathrm{T}$ regulatory cell response in $\mathrm{Gdx} \mathrm{XY}$ mice will explain the increased resistance of these animals to CVB3 induced disease, although this will need to be confirmed by depletion of these cells prior to CVB3 infection. The major question that remains is why the $\mathrm{XY}$ sex chromosome complement would give rise to enhanced Foxp3 expression when this gene is present on the $\mathrm{X}$ chromosome. It is unlikely that the XY sex chromosome complement is directly affecting expression of the Foxp 3 gene, but may establish conditions that are favorable to $\mathrm{T}$ regulatory cell activation.

The dominance of CVB3-induced autoimmune pathogenesis is also shown by the disassociation between myocarditis and cardiac virus titers. $\mathrm{T}$ cell depletion reduces cardiac injury but has no effect on virus titers in the heart. If cardiac injury resulted from direct virus infection and replication, then $\mathrm{T}$ cell depleted male mice would not be protected when virus load in the myocardium remained high. The inability of $\mathrm{T}$ cells to promote CVB3 clearance was initially shown in 1974 using both athymic (nude) and thymectomized, irradiated, bone marrow reconstituted animals [40]. Since then, various studies have demonstrated that $\mathrm{T}$ cell independent antibodies are rapidly induced by picornavirus infections, including CVB3 and foot-and-mouth disease virus, which, along with macrophages, are the primary mediators of virus clearance $[40,46,47]$.

Protection against IAV infection represents a delicate balance between immune responses protecting versus causing pathology in the host. Immediately following 


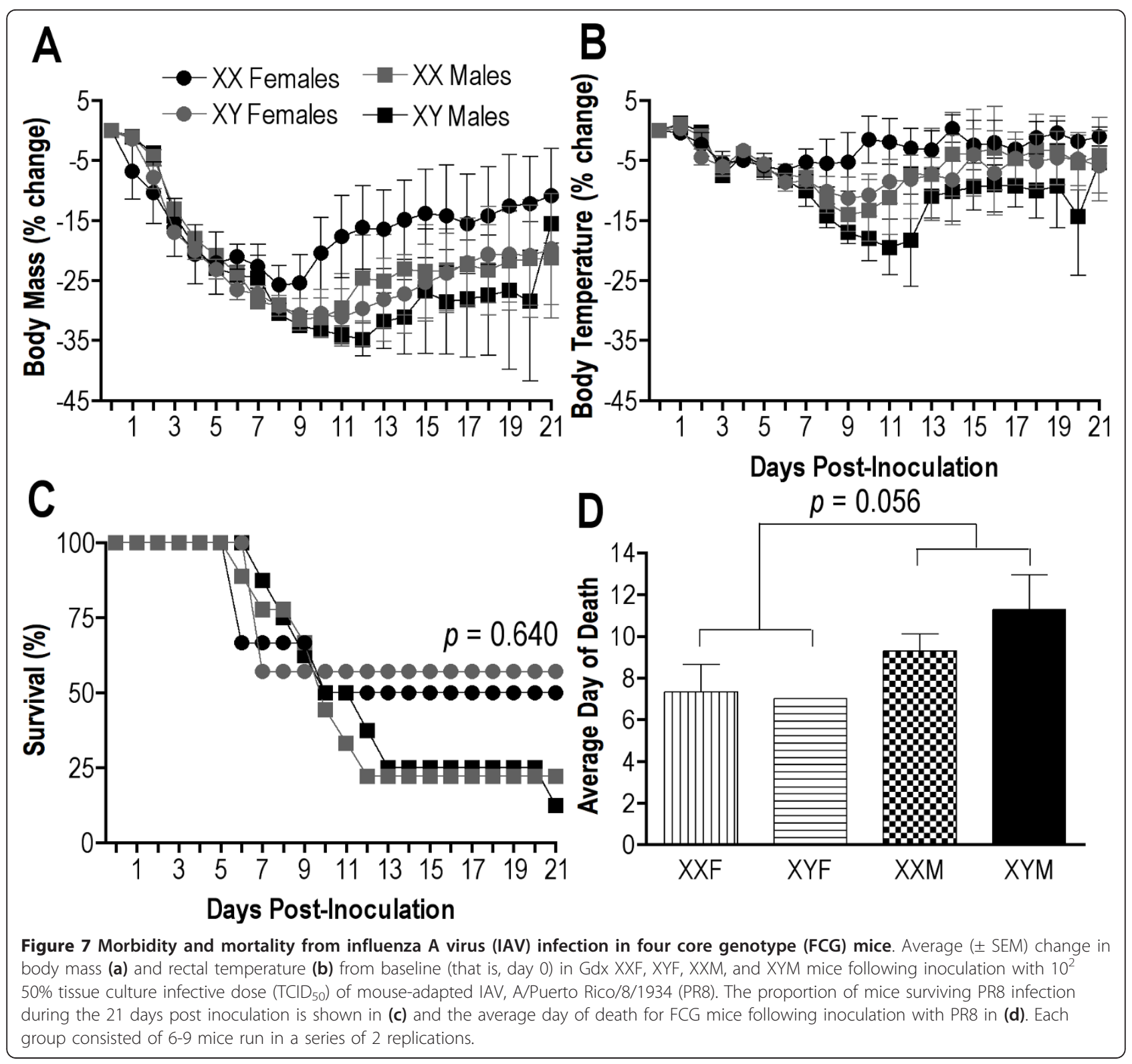

infection, proinflammatory responses, including production of cytokines (for example, TNF $\alpha$, IL-6, and IL-1 $\beta$ ) and chemokines (for example, chemokine ( $\mathrm{C}-\mathrm{C}$ motif) ligand 2 (CCL2) and CCL3), are initiated by macrophages, dendritic cells, and epithelial cells in the respiratory tract, which activate humoral and cell-mediated immune responses to promote virus clearance and protection of the host from subsequent infection. There is, however, growing evidence that these early proinflammatory events can lead to severe disease and even death through a process termed 'immunopathology' [48]. Immune memory and long-term protective immunity against IAV is mediated by pre-existing antibodies as well as memory B and T cells [49]. Young adult female mice produce significantly higher proinflammatory cytokine and chemokine responses and experience greater morbidity and mortality during IAV infection than males, which appears to involve the effects of infection on circulating levels of estradiol [32]. Influenza A virus infection of female mice disrupts reproductive function resulting in persistently low levels of estradiol and progesterone, heightened proinflammatory responses, and reduced rates of survival [32]. Consequently, the outcome of IAV infection is severe for both gonadallyintact and Gdx female mice and exogenous administration of estradiol to $\mathrm{Gdx}$ females significantly reduces the induction of proinflammatory responses and increases rates of survival [32]. Taken together, our previous data 
combined with data from the current study illustrate that gonadal secretions, but not sex chromosome complement, play a role in modulating responses to IAV infection.

Gonadectomy of female mice substantially increased pathogenicity in females infected with CVB3, but had little effect in IAV infected females. In males, Gdx had the opposite effect, with Gdx protecting CVB3 infected males, but increasing pathogenesis in IAV infected $\mathrm{Gdx}$ males. A key difference between IAV and CVB3 infections is in the crucial role of adaptive immunity to clear influenza virus [50,51], whereas T lymphocytes and virus neutralizing antibodies are of limited value for elimination of picornaviruses [40,47]. This difference in the requirement for adaptive immune responses for recovery from IAV and CVB3 likely contributes to why $\mathrm{Gdx}$ is protective against CVB3 and promotes pathogenicity of IAV infection.

The response of FCG mice to infection with CVB3 and the development of CVB3-induced myocarditis in $\mathrm{XX}$ animals is similar to the responses of FCG mice in experimental models of EAE and lupus, in which the XX sex chromosome complement produces significantly more severe disease than the XY complement [27]. In EAE and lupus models, XX mice had lower levels of Th2 cytokines than XY mice. Consequently, Th2mediated responses promote resistance against EAE [52], whereas Th1 and Th17 cell activation is crucial to EAE severity [53]. In the current study, XY mice developed less severe CVB3-induced myocarditis and had more $\mathrm{T}$ regulatory cells in their hearts than $\mathrm{XX}$ mice. $\mathrm{T}$ regulatory cells inhibit proinflammatory responses through direct cell-cell contact with effector $\mathrm{T}$ cells, interaction with antigen presenting cells resulting increased indoleamine-2,3-dioxygenase (IDO) production, and secretion of soluble factors including IL-10 and transforming growth factor (TGF) $\beta$ [54-56]. The effect of sex chromosome complement on $\mathrm{T}$ regulatory cells was not addressed in previous experiments of EAE and lupus in FCG mice [27]; T regulatory cells, however, are associated with resistance against EAE [57]. An inherent deficiency in $\mathrm{T}$ regulatory cell activation in individuals either having two $\mathrm{X}$ chromosomes or lacking a Y chromosome is consistent with autoimmune diseases that typically show a strong female bias [23,58].

Three genetic differences between XX and XY mice could contribute to a sex chromosome effect. The Y chromosome may encode genes that normally have an $\mathrm{XY}$-specific effect. Secondly, the double dose of $\mathrm{X}$ genes in $\mathrm{XX}$ mice, relative to $\mathrm{XY}$ mice, could cause constitutively higher expression of some $X$ genes [59]. The process of $\mathrm{X}$ inactivation greatly reduces the number of $\mathrm{X}$ genes that show such sex differences in expression. There are, however, a small number genes that escape $\mathrm{X}$ inactivation resulting in meaningful differences in gene expression [60]. Thirdly, $\mathrm{X}$ genes that receive a parental imprint might be expressed higher in one sex than the other, because only females receive a paternal X imprint. Further genetic studies are needed to resolve the chromosome of origin of the sex chromosome effects reported here, and the genes, especially those that code for immune-related proteins, that are responsible.

Sex differences in circulating levels of gonadal hormones contribute significantly to sex differences in response to viral infections [1]; there is, however, little evidence that gonadal secretions have lasting effects that are maintained for several weeks after removal of the gonads. These effects, often called 'organizational' effects of gonadal hormones [61], may account for the differences between Gdx males and females in response to CVB3 and IAV infection. Thus, the immune system, like the brain and genitalia, may reflect lifelong sex differences established by sex differences in patterns of gonadal secretions early during development [62]. Alternatively, the differences in gonadal males and females seen in response to CVB3 may be caused by direct effects of Sry on non-gonadal tissues.

\section{Conclusions}

Although sex chromosomes can directly influence CVB3 pathogenesis, the dominant sex effect is mediated by gonadal hormones. Gonadally intact WT males are more susceptible to CVB3 myocarditis than gonadally intact WT females. Although gonadectomy reduces male susceptibility, restoring testosterone to $\mathrm{Gdx}$ males results in equivalent myocarditis as in intact animals [30], and treating intact males with estradiol inhibits disease [63]. Similarly, gonadectomy reduces the sex difference in susceptibility to IAV in mice. Taken together, the data presented suggest that any effect of sex chromosome complement on responses to viruses is overpowered by the effects of sex hormones on virus infection and immunity. The significance of direct chromosome effects on clinical CVB3 or other viral infections may be minimal in premenopausal women when estrogen levels are high. Examination of immune responses to viruses in older populations, especially among postmenopausal women, may unmask clinicallyrelevant effects of sex chromosomal genes on viral disease pathogenesis. Clarification of the relative roles of gonadal hormones and sex chromosome effects will be improved once the $\mathrm{X}$ or $\mathrm{Y}$ genes responsible for sex chromosome effects are identified.

\section{Acknowledgements}

The authors thank Pamela Burton for help with preparing the manuscript and Colette Charland for assistance with flow cytometry. This research was supported by NIH fellowship AI089034 to DPR, NIH Al079342 and a Society 
for Women's Health Research Medtronic Award to SLK, NIH HL86549, HL108371, and Al36333 to SAH and NIH NS043196 to AA. Publication costs were supported in part by the Society for Women's Health Research.

\section{Author details}

${ }^{1}$ The W Harry Feinstone Department of Molecular Microbiology and Immunology, The Johns Hopkins Bloomberg School of Public Health, Baltimore, MD 21205, USA. ${ }^{2}$ Department of Pathology, University of Vermont, Burlington, VT 05446, USA. ${ }^{3}$ Department of Medicine, University of Vermont, Burlington, VT 05446, USA. ${ }^{4}$ Department of Integrative Biology and Physiology, Laboratory of Neuroendocrinology of the Brain Research Institute, University of California, Los Angeles, CA 90095, USA.

\section{Authors' contributions}

DR designed and carried out the IAV studies, analyzed and interpreted IAV data, drafted all figures, and contributed to the writing and editing of the manuscript. SK designed the IAV studies, analyzed IAV data, interpreted IAV data, and contributed to drafting the manuscript. SH designed the CVB3 studies, analyzed and interpreted the CVB3 data, and contributed to the writing and editing of the manuscript. MM and BR carried out the CVB3 studies. CT contributed to the interpretation of the CVB3 data. RW and AA provided FCG mice and contributed to interpretation of data and drafting of the manuscript. All authors approved the final manuscript.

\section{Competing interests}

The authors declare that they have no competing interests.

Received: 24 March 2011 Accepted: 1 August 2011

Published: 1 August 2011

\section{References}

1. Klein SL, Huber S: Sex differences in susceptibility to viral infection. In Sex Hormones and Immunity to Infection. Edited by: Klein SL, Roberts CW. Berlin, Germany: Springer-Verlag; 2010:93-122.

2. Roberts CW, Walker W, Alexander J: Sex-associated hormones and immunity to protozoan parasites. Clin Microbiol Rev 2001, 14:476-488.

3. Araneo BA, Dowell T, Diegel M, Daynes RA: Dihydrotestosterone exerts a depressive influence on the production of interleukin-4 (IL-4), IL-5, and gamma-interferon, but not IL-2 by activated murine T cells. Blood 1991, 78:688-699.

4. Barrat F, Lesourd B, Boulouis HJ, Thibault D, Vincent-Naulleau S, Gjata B, Louise A, Neway T, Pilet C: Sex and parity modulate cytokine production during murine ageing. Clin Exp Immunol 1997, 109:562-568.

5. Brabin L: Interactions of the female hormonal environment, susceptibility to viral infections, and disease progression. AIDS Patient Care STDS 2002, 16:211-221.

6. Paharkova-Vatchkova V, Maldonado R, Kovats S: Estrogen preferentially promotes the differentiation of $\mathrm{CD} 11 \mathrm{c}+\mathrm{CD} 11 \mathrm{~b}$ (intermediate) dendritic cells from bone marrow precursors. J Immunol 2004, 172:1426-1436.

7. Ito A, Bebo BF Jr, Matejuk A, Zamora A, Silverman M, Fyfe-Johnson A, Offner $\mathrm{H}$ : Estrogen treatment down-regulates TNF-alpha production and reduces the severity of experimental autoimmune encephalomyelitis in cytokine knockout mice. J Immunol 2001, 167:542-552.

8. Li J, McMurray RW: Effects of estrogen receptor subtype-selective agonists on immune functions in ovariectomized mice. Int Immunopharmacol 2006, 6:1413-1423.

9. Karpuzoglu-Sahin E, Hissong BD, Ansar Ahmed S: Interferon-gamma levels are upregulated by 17-beta-estradiol and diethylstilbestrol. J Reprod Immunol 2001, 52:113-127.

10. Karpuzoglu-Sahin E, Zhi-Jun Y, Lengi A, Sriranganathan N, Ansar Ahmed S: Effects of long-term estrogen treatment on IFN-gamma, IL-2 and IL-4 gene expression and protein synthesis in spleen and thymus of normal C57BL/6 mice. Cytokine 2001, 14:208-217.

11. Lambert KC, Curran EM, Judy BM, Milligan GN, Lubahn DB, Estes DM: Estrogen receptor alpha (ERalpha) deficiency in macrophages results in increased stimulation of $\mathrm{CD} 4+\mathrm{T}$ cells while 17 beta-estradiol acts through ERalpha to increase IL-4 and GATA-3 expression in CD4+ T cells independent of antigen presentation. J Immunol 2005, 175:5716-5723.

12. Smithson G, Couse J, Lubahn D, Korach K, Kincade P: The role of estrogen receptors and androgen receptors in sex steroid regulation of $B$ lymphocytes. J Immunol 1998, 161:27-34.
13. Grimaldi CM, Cleary J, Dagtas AS, Moussai D, Diamond B: Estrogen alters thresholds for B cell apoptosis and activation. J Clin Invest 2002, 109:1625-1633.

14. Islander U, Erlandsson MC, Hasseus B, Jonsson CA, Ohlsson C, Gustafsson JA, Dahlgren U, Carlsten H: Influence of oestrogen receptor alpha and beta on the immune system in aged female mice. Immunology 2003, 110:149-157.

15. Polanczyk MJ, Hopke C, Huan J, Vandenbark AA, Offner H: Enhanced FoxP3 expression and Treg cell function in pregnant and estrogen-treated mice. J Neuroimmunol 2005, 170:85-92.

16. Polanczyk M, Yellayi S, Zamora A, Subramanian S, Tovey M, Vandenbark AA, Offner $\mathrm{H}$, Zachary JF, Fillmore PD, Blankenhorn EP, Gustafsson JA, Teuscher C: Estrogen receptor-1 (Esr1) and -2 (Esr2) regulate the severity of clinical experimental allergic encephalomyelitis in male mice. Am J Pathol 2004, 164:1915-1924.

17. Tai $P$, Wang J, Jin H, Song X, Yan J, Kang Y, Zhao L, An X, Du X, Chen X, Wang S, Xia G, Wang B: Induction of regulatory T cells by physiological level estrogen. J Cell Physiol 2008, 214:456-464.

18. Tanriverdi F, Silveira LF, MacColl GS, Bouloux PM: The hypothalamicpituitary-gonadal axis: immune function and autoimmunity. J Endocrinol 2003, 176:293-304

19. Szekeres-Bartho J: Immunological relationship between the mother and the fetus. Int Rev Immunol 2002, 21:471-495.

20. Lenz F: Morbidic Hereditary Factors New York, USA: Macmillan Press; 1931.

21. Purtilo DT, Sullivan JL: Immunological bases for superior survival of females. Am J Dis Child 1979, 133:1251-1253.

22. Arnold AP, Chen X: What does the "four core genotypes" mouse model tell us about sex differences in the brain and other tissues? Front Neuroendocrinol 2009, 30:1-9.

23. Libert $C$, Dejager $L$, Pinheiro I: The $X$ chromosome in immune functions: when a chromosome makes the difference. Nat Rev Immunol 2010, 10:594-604.

24. Fish EN: The X-files in immunity: sex-based differences predispose immune responses. Nat Rev Immunol 2008, 8:737-744.

25. Voskuhl R: Sex differences in autoimmune diseases. Biol Sex Differ 2011, 2:1.

26. Koopman P, Gubbay J, Vivian N, Goodfellow P, Lovell-Badge R: Male development of chromosomally female mice transgenic for Sry. Nature 1991, 351:117-121

27. Smith-Bouvier DL, Divekar AA, Sasidhar M, Du S, Tiwari-Woodruff SK, King JK, Arnold AP, Singh RR, Voskuhl RR: A role for sex chromosome complement in the female bias in autoimmune disease. J Exp Med 2008, 205:1099-1108.

28. Fuller A, Yahikozawa H, So EY, Dal Canto M, Koh CS, Welsh CJ, Kim BS: Castration of male C57L/J mice increases susceptibility and estrogen treatment restores resistance to Theiler's virus-induced demyelinating disease. J Neurosci Res 2007, 85:871-881.

29. Fuller AC, Kang B, Kang HK, Yahikozowa H, Dal Canto MC, Kim BS: Gender bias in Theiler's virus-induced demyelinating disease correlates with the level of antiviral immune responses. J Immunol 2005, 175:3955-3963.

30. Huber $S$, Job $L$, Auld $K$ : Influence of sex hormones on coxsackie B3 virus infection in Balb/c mice. Cell Immunol 1982, 67:173-179.

31. Klein SL, Pekosz A, Passaretti C, Anker M, Olukoya P: Sex, Gender and Influenza Geneva, Switzerland: World Health Organization; 2010, 1-58.

32. Robinson DP, Lorenzo ME, Jian W, Klein SL: Elevated $17 \beta$-estradiol protects females from influenza $A$ virus pathogenesis by suppressing inflammatory responses. PLoS Pathog 2011, 7:e1002149.

33. Palaszynski KM, Smith DL, Kamrava S, Burgoyne PS, Arnold AP, Voskuhl RR: A yin-yang effect between sex chromosome complement and sex hormones on the immune response. Endocrinology 2005, 146:3280-3285.

34. Siracusa MC, Overstreet MG, Housseau F, Scott AL, Klein SL: 17\{́beta\}estradiol alters the activity of conventional and IFN-producing killer dendritic cells. J Immunol 2008, 180:1423-1431.

35. Cernetich A, Garver LS, Jedlicka AE, Klein PW, Kumar N, Scott AL, Klein SL: Involvement of gonadal steroids and gamma interferon in sex differences in response to blood-stage malaria infection. Infect Immun 2006, 74:3190-3203.

36. Klein SL, Bird BH, Glass GE: Sex differences in Seoul virus infection are not related to adult sex steroid concentrations in Norway rats. J Virol 2000, 74:8213-8217. 
37. Knowlton KU, Jeon ES, Berkley N, Wessely R, Huber S: A mutation in the puff region of VP2 attenuates the myocarditic phenotype of an infectious CDNA of the Woodruff variant of coxsackievirus B3. J Virol 1996, 70:7811-7818.

38. Van Houten N, Bouchard P, Moraska A, Huber S: Selection of an attenuated coxsackievirus B3 variant using a monoclonal antibody reactive to myocyte antigen. J Virol 1991, 65:1286-1290.

39. Huber SA: Coxsackievirus B3-induced myocarditis: infection of females during the estrus phase of the ovarian cycle leads to activation of $T$ regulatory cells. Virology 2008, 378:292-298.

40. Woodruff J, Woodruff J: Involvement of T lymphocytes in the pathogenesis of coxsackievirus B3 heart disease. J Immunol 1974, 113:1726-1734.

41. Larcombe AN, Foong RE, Bozanich EM, Berry L, Garratt LW, Gualano RC, Jones JE, Dousha LF, Zosky GR, Sly PD: Sexual dimorphism in lung function responses to acute influenza A infection. Influenza Other Respi Viruses 2011.

42. Huber S: T cells expressing the gamma-delta $T$ cell receptor induce apoptosis in cardiac myocytes. Cardiovasc Res 2000, 45:579-587.

43. Miller S, Vanderlugt C, Begolka W, Pao W, Yauch R, Neville K, Katz-Levy Y, Carrizosa A, Kim B: Persistent infection with Theiler's virus leads to CNS autoimmunity via epitope spreading. Nat Med 1997, 3:1133-1136.

44. Kawagishi A, Kubosaki A, Takeyama N, Sakudo A, Saeki K, Matsumoto Y, Hayashi T, Onodera T: Analysis of T-cell receptor Vbeta gene from infiltrating $T$ cells in insulitis and myocarditis in encephalomyocarditis virus-infected BALB/C mice. Biochem Biophys Res Commun 2003, 310:791-795.

45. Huber SA, Feldman AM, Sartini D: Coxsackievirus B3 induces T regulatory cells, which inhibit cardiomyopathy in tumor necrosis factor-alpha transgenic mice. Circ Res 2006, 99:1109-1116.

46. Juleff N, Windsor M, Lefevre EA, Gubbins S, Hamblin P, Reid E, McLaughlin K, Beverley PC, Morrison IW, Charleston B: Foot-and-mouth disease virus can induce a specific and rapid CD4+ T-cell-independent neutralizing and isotype class-switched antibody response in naive cattle. J Virol 2009, 83:3626-3636.

47. Woodruff J: Lack of correlation between neutralizing antibody production and suppression of coxsackievirus B-3 replication in target organs: evidence for involvement of mononuclear inflammatory cells in defense. J Immunol 1979, 123:31-36.

48. La Gruta NL, Kedzierska K, Stambas J, Doherty PC: A question of selfpreservation: immunopathology in influenza virus infection. Immunol Cell Biol 2007, 85:85-92.

49. Ahmed R, Oldstone MB, Palese P: Protective immunity and susceptibility to infectious diseases: lessons from the 1918 influenza pandemic. Nat Immunol 2007, 8:1188-1193.

50. Fernandez-Sesma A, Marukian S, Ebersole BJ, Kaminski D, Park MS, Yuen T, Sealfon SC, Garcia-Sastre A, Moran TM: Influenza virus evades innate and adaptive immunity via the NS1 protein. J Virol 2006, 80:6295-6304.

51. Lee DC, Cheung CY, Law AH, Mok CK, Peiris M, Lau AS: p38 mitogenactivated protein kinase-dependent hyperinduction of tumor necrosis factor alpha expression in response to avian influenza virus H5N1. J Virol 2005, 79:10147-10154.

52. Ramirez F, Mason D: Induction of resistance to active experimental allergic encephalomyelitis by myelin basic protein-specific Th2 cell lines generated in the presence of glucocorticoids and IL-4. Eur J Immunol 2000, 30:747-758.

53. Yang Y, Weiner J, Liu Y, Smith AJ, Huss DJ, Winger R, Peng H, Cravens PD, Racke MK, Lovett-Racke AE: T-bet is essential for encephalitogenicity of both Th1 and Th17 cells. J Exp Med 2009, 206:1549-1564.

54. Cools N, Ponsaerts P, Van Tendeloo VF, Berneman ZN: Balancing between immunity and tolerance: an interplay between dendritic cells, regulatory T cells, and effector T cells. J Leukoc Biol 2007, 82:1365-1374.

55. Niederkorn JY: Emerging concepts in CD8(+) T regulatory cells. Curr Opin Immunol 2008, 20:327-331.

56. Nakamura $H$, Kato $T$, Yamamura $T$, Yamamoto $T$, Umemoto $S$, Sekine $T$, Nishioka K, Matsuzaki M: Characterization of T cell receptor beta chains of accumulating $\mathrm{T}$ cells in chronic ongoing myocarditis demonstrated by heterotopic cardiac transplantation in mice. Jpn Circ J 2001, 65:106-110.

57. Kohm AP, Carpentier PA, Miller SD: Regulation of experimental autoimmune encephalomyelitis (EAE) by CD4+CD25+ regulatory $T$ cells. Novartis Found Symp 2003, 252:45-52.
58. Knudsen GP: Gender bias in autoimmune diseases: X chromosome inactivation in women with multiple sclerosis. J Neurol Sci 2009 286:43-46.

59. Disteche CM, Filippova GN, Tsuchiya KD: Escape from $X$ inactivation. Cytogenet Genome Res 2002, 99:36-43.

60. Wijchers PJ, Festenstein RJ: Epigenetic regulation of autosomal gene expression by sex chromosomes. Trends Genet 2011.

61. Arnold AP: The organizational-activational hypothesis as the foundation for a unified theory of sexual differentiation of all mammalian tissues. Horm Behav 2009, 55:570-578.

62. Martin JT: Sexual dimorphism in immune function: the role of prenatal exposure to androgens and estrogens. Eur J Pharmacol 2000, 405:251-261.

63. Huber SA, Kupperman J, Newell MK: Estradiol prevents and testosterone promotes Fas-dependent apoptosis in CD4+ Th2 cells by altering $\mathrm{BCl} 2$ expression. Lupus 1999, 8:384-387.

doi:10.1186/2042-6410-2-8

Cite this article as: Robinson et al: Sex chromosome complement contributes to sex differences in coxsackievirus B3 but not influenza A virus pathogenesis. Biology of Sex Differences 2011 2:8.

\section{Submit your next manuscript to BioMed Central and take full advantage of:}

- Convenient online submission

- Thorough peer review

- No space constraints or color figure charges

- Immediate publication on acceptance

- Inclusion in PubMed, CAS, Scopus and Google Scholar

- Research which is freely available for redistribution

Submit your manuscript at www.biomedcentral.com/submit
C Biomed Central 